\title{
THE ROLE OF PLATELET COUNT AND MEAN PLATELET VOLUME DURING FIRST TRIMESTER IN PREDICTION OF PRETERM PREMATURE RUPTURE OF MEMBRANES
}

By

\author{
Ibrahiem Abd El-Rhaman Abd El-Fattah, Abd El-Moneim Mohammed \\ Zakaria, Bassam Ragab Abd El-Aziz, Amr Ahmed Rezk* \\ Departments Obstetrics \& Gynecology and Clinical Pathology*, Faculty of Medicine, Al- \\ Azhar University \\ Corresponding Author: Ibrahiem Abd El-Rhaman Abd El-Fattah,
}

E-mail: ibrahiemabdelrhaman12019@gmail.com

\begin{abstract}
Background: The fetal membranes are the thin tissue that surround the fetus during gestation, and critical for maintaining a pregnancy to delivery.

Objective: To evaluate the values of platelet count and mean platelet volume (MPV) obtained from maternal serum during pregnancy to predict subsequent preterm premature rupture of membranes (PPROM).

Patients and Methods: This study was a prospective Cohort study that was conducted on 300 cases of pregnant women at Obstetric and gynecological department at El-Hussein University Hospital. All patients met the inclusion criteria and were divided into two groups, Group I (PPROM group) that included 22 pregnant women with history of vaginal fluid leakage and diagnosed as PPROM and Group II (Control group) which included 278 pregnant women with gestational age between 37 - 41 weeks and without any history of complications throughout the pregnancy as a control group.

Results: As regard the area under curve, cutoff and validity of PLT regard detection of PPROM, Significant AUC with cutoff $>258$ with sensitivity $83.3 \%$ and specificity $75.0 \%$. The overall accuracy of MPV for detecting PPROM was found to be superior to platelet count.

Conclusion: MPV is a cheap, rapid and easily applicable test for determining the patients at risk for PPROM. Due to multifactorial origin of PPROM, early detection of all patients with a single test is rather difficult. In order to develop an accurate and efficient method in the estimation of the risk of PPROM, screening strategies combining MPV with other biological markers should be considered.
\end{abstract}

Keywords: First Trimester, Preterm Premature Rupture of Membranes.

\section{INTRODUCTION}

The fetal membranes are the thin tissue that surround the fetus during gestation, and critical for maintaining a pregnancy to delivery. In order for successful delivery to occur, normal rupture of the membrane (ROM) takes place at term. Occasionally,
ROM occurs before the onset of labour, known as premature rupture of the membrane (PROM), which is not considered to be pathological as it is usually followed by contractions (Calvin and Oyen, 2010). 
The premature rupture of membrane is considered preterm if occurred before 37 weeks of gestation. So Preterm premature rupture of membranes (PPROM) is defined as rupture of the amniotic membranes prior to the completion of 37 weeks of gestation (Kale et al., 2010).

PROM remains a serious challenge for obstetricians, because of its high rate of comorbidity, including infection, cesarean section, and other associated problems (American College of Obstetricians and Gynecologists, 2016). Preterm PROM "PPROM", accompanied by preterm birth, is the leading cause of morbidity and mortality in the neonatal period (Yeh et al., 2017).

As preterm birth is associated with numerous complications, early identification of patients with an increased risk for PPROM is considerably important in reducing adverse perinatal outcomes. The cause of PPROM is multifactorial and intra-amniotic infection, reduction in membrane collagen content, stretched membranes, vasculopathy in placentation and decidual hemorrhage are considered to be possible mechanisms underlying PPROM. Among these, chronic infection of fetal membranes has a clear role in the initiation and propagation of molecular events leading to PPROM (Ekin et al., 2015).

Previous studies have shown that intrauterine infection triggers a rise of several cytokines in maternal serum as well as amniotic fluid (Agrawala and Hirsch, 2012).

Platelet activation has long been noticed in the pathophysiology of infection, inflammation and malignancy. Mean platelet volume (MPV) is a reliable indicator of platelet size that reflects platelet function and activation. Previous studies reported the association of MPV with both pro-thrombosis and proinflammation (Gasparyan et al., 2011).

The aim of this study is to evaluate the values of platelet count and mean platelet volume (MPV) obtained from maternal serum during pregnancy to predict subsequent preterm premature rupture of membranes (PPROM).

\section{PATIENTS AND METHODS}

This was a prospective cohort comparative study that was conducted at Obstetric and gynecological department at Sayed Galal and El-hussien University Hospital in the period from June 2019 to January 2020.

Before the start of the study, permission was obtained from the Ethical Committee in the faculty of medicine, AlAzhar University. Also Informed consent from patients included in the study was obtained.

This study was conducted on 300 of cases attending ANC unit at Sayed Galal and El-Hussien university hospitals, they were divided into two groups:

- Non-PPROM group: included 278 pregnant women who delivered without occurrence of PPROM.

- PPROM group: included 22 pregnant women who suffered of PPROM.

All the women participating in this study were chosen according to the following criteria:

\section{Inclusion Criteria:}

- Pregnant women aged 18 - 35ys

- Non-complicated singleton pregnancy. 


\section{THE ROLE OF PLATELET COUNT AND MEAN PLATELET VOLUME... 59}

- Gestational age 11 - 14 weeks for the study group at the start of the study.

\section{Exclusion Criteria:}

- Women with multiple pregnancies, fetal anomalies.

- Women with pat history of bleeding tendency of Know blood disease.

- Women with chronic hypertension, cardiac, renal or liver diseases, epilepsy and unexplained anemia.

- Presence of any vaginal bleeding of any amount.

- Women with cervical Incompetence, short cervix or on cervical cerclage.

After informed written consent were obtained from all patients included in the study they were subjected to the followings:

I. Full medical history.

II. Full general examination.

III. Ultrasonic examination.

IV. Routine investigations.

V. Pregnancy outcomes.

All selected women were observed during the course of pregnancy and after the end of pregnancy in order to assess the following outcomes.

Primary outcomes: Occurrence of PPROM.

\section{Secondary outcomes:}

- Time and mode of delivery
- Neonatal APGAR score at 1 and 5 minutes.

- Neonatal ICU admission

\section{Statistical Analysis:}

The collected data was revised, coded, tabulated and introduced to a PC using Statistical package for Social Science (SPSS version 20.0 for windows; SPSS Inc, Chicago, IL, 2001). Data was presented and suitable analysis was done according to the type of data obtained for each parameter. Descriptive Statistics: Mean, Standard deviation ( \pm SD) and range for parametric numerical data. Frequency and percentage of nonnumerical data. Student T Test: was used to assess the statistical significance of the difference between two study group means. Chi-Square test (X2): was used to examine the relationship between two qualitative variables. ROC curve: A receiver operating characteristic (ROC), or simply ROC curve, is a graphical plot which illustrates the performance of a binary classifier system as its discrimination threshold is varied. It is created by plotting the fraction of true positives out of the positives $(\mathrm{TPR}=$ true positive rate) vs. the fraction of false positives out of the negatives (FPR $=$ false positive rate), at various threshold settings. TPR is also known as sensitivity (also called recall in some fields), and FPR is one minus the specificity or true negative rate. $\mathrm{P}>0.05$ : Non significant (NS). $\mathrm{P}<$ 0.05: Significant (S). $\mathrm{P}<0.01$ : Highly significant (HS).

\section{RESULTS}

Maternal ages were ranging between 19 - 35 years with mean age $26.89 \pm 4.42$, gestational ages (GA) at the beginning of the study was ranging between $11-14$ weeks with mean GA $12.3 \pm 0.99$ while at the end of the study was ranging between 
$29-40$ weeks with mean GA $37.3 \pm 2.26$. Regarding parity, majority of studied cases were para $\leq 2(49.3 \%)$ while $19.4 \%$ were para $3-4$ times and $2.3 \%$ of cases were para more than 4 times. $20 \%$ of studied group had previous PROM, 30\% had positive $\mathrm{FH}, 35.7 \%$ of studied group had no co-morbidities, 34\% had anemia and $18.3 \%$ had passive smoker and finally gestational DM was in $12 \%$, only $5.3 \%$ had IVF. $12.7 \%$ had preterm labor, $7.3 \%$ had PPROM, 28\% had PPH and $51.3 \%$ had NVD and CS was $48.7 \%$. Female babies were $56.3 \%$ and male represent $43.7 \%$, NCIU was needed by $19.7 \%$ regard survival $3.7 \%$ died and $96.3 \%$ survived (Table 1).

Table (1): Maternal and gestational ages, clinical and obstetric history, maternal outcome, Neonatal outcome distribution among studied group

\begin{tabular}{|c|c|c|c|c|}
\hline \multicolumn{3}{|l|}{ Variable } & & \\
\hline \multicolumn{3}{|l|}{$\begin{array}{ll}\text { Age: } & \\
& \text { Mean } \pm \text { SD } \\
\end{array}$} & \multicolumn{2}{|c|}{$\begin{array}{c}26.89 \pm 4.42 \\
19-35\end{array}$} \\
\hline \multicolumn{3}{|c|}{$\begin{array}{ll}\text { Gestational Age (GA) at beginning: } \\
-\quad\end{array}$} & \multicolumn{2}{|c|}{$\begin{array}{c}12.3 \pm 0.99 \\
11-14 \\
\end{array}$} \\
\hline \multirow{2}{*}{\multicolumn{3}{|c|}{$\begin{array}{ll}\text { GA } \text { at end: } \\
\quad & \text { Mean } \pm \text { SD } \\
& \text { Range } \\
\end{array}$}} & \multicolumn{2}{|c|}{$\begin{array}{c}37.3 \pm 2.26 \\
29-40\end{array}$} \\
\hline & & & $\mathbf{N}$ & $\%$ \\
\hline \multicolumn{3}{|l|}{$\begin{array}{ll}\text { Parity: } & \\
: & \text { PG } \\
: & \leq 2 \\
: & 3-4 \\
: & >4 \\
. & \text { Total } \\
\end{array}$} & $\begin{array}{c}87 \\
148 \\
58 \\
7 \\
300 \\
\end{array}$ & $\begin{array}{c}29.0 \\
49.3 \\
19.4 \\
2.3 \\
100.0\end{array}$ \\
\hline \multirow{2}{*}{ Previous PROM } & & NO & 240 & 80.0 \\
\hline & & YES & 60 & 20.0 \\
\hline \multirow{2}{*}{ FH } & & NO & 210 & 70.0 \\
\hline & - & YES & 90 & 30.0 \\
\hline \multirow{4}{*}{ Risks and co-morbidity } & - & NO & 107 & 35.7 \\
\hline & - & Passive smoker & 55 & 18.3 \\
\hline & - & Gestational DM & 36 & 12.0 \\
\hline & - & Anemia & 102 & 34.0 \\
\hline \multirow{2}{*}{ IVF } & 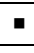 & $-\mathrm{VE}$ & 284 & 94.7 \\
\hline & - & $+\mathrm{VE}$ & 16 & 5.3 \\
\hline \multirow{2}{*}{ Preterm } & - & No & 262 & 87.3 \\
\hline & - & Yes & 38 & 12.7 \\
\hline \multirow{2}{*}{ PPROM } & - & No & 278 & 92.7 \\
\hline & - & Yes & 22 & 7.3 \\
\hline \multirow{2}{*}{ PPH } & 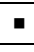 & No & 216 & 72.0 \\
\hline & - & Yes & 84 & 28.0 \\
\hline \multirow{2}{*}{ MODE } & - & NVD & 154 & 51.3 \\
\hline & - & $\mathbf{C S}$ & 146 & 48.7 \\
\hline \multirow{2}{*}{ Baby sex } & - & Male & 131 & 43.7 \\
\hline & - & Female & 169 & 56.3 \\
\hline \multirow{2}{*}{ NICU } & 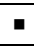 & Not & 241 & 80.3 \\
\hline & - & Needed & 59 & 19.7 \\
\hline \multirow{2}{*}{ Mortality } & & Survived & 289 & 96.3 \\
\hline & - & Died & 11 & 3.7 \\
\hline
\end{tabular}


THE ROLE OF PLATELET COUNT AND MEAN PLATELET VOLUME... 61

Total

Age was significantly higher among PROM cases but GA at the end was significantly lower at PPROM group and there was no significant difference between groups regard GA at beginning.
300 100.0

PLT was significantly higher among PPROM cases but MPV was significantly lower among PPROM cases with no other significance between groups (Table 2).

Table (2): Comparison between both studied group as regard maternal, gestational ages and $L A B$ parameters

\begin{tabular}{|c|c|c|c|}
\hline Variable & $\begin{array}{c}\text { No PPROM group } \\
(\mathbf{N}=\mathbf{2 7 8})\end{array}$ & $\begin{array}{c}\text { PPROM group } \\
(\mathbf{N}=\mathbf{2 2})\end{array}$ & $P$ - value \\
\hline Age & $26.74 \pm 4.37$ & $29.09 \pm 4.56$ & 0.016* \\
\hline GA beginning & $12.28 \pm 0.96$ & $12.5 \pm 1.26$ & 0.327 \\
\hline GA end & $37.81 \pm 1.32$ & $30.81 \pm 1.59$ & $0.00 * *$ \\
\hline HB & $11.39 \pm 1.46$ & $11.25 \pm 1.39$ & 0.647 \\
\hline WBCs & $8.42 \pm 1.11$ & $8.1 \pm 1.66$ & 0.179 \\
\hline PLT & $245.24 \pm 41.46$ & $285.13 \pm 50.11$ & $\mathbf{0 . 0 0 * *}$ \\
\hline MPV & $9.07 \pm 0.45$ & $8.51 \pm 0.34$ & $0.00 * *$ \\
\hline INR & $1.04 \pm 0.06$ & $1.06 \pm 0.09$ & 0.090 \\
\hline $\mathrm{Cr}$ & $1.02 \pm 0.11$ & $1.01 \pm 0.12$ & 0.803 \\
\hline
\end{tabular}

Previous PROM and positive family history were significantly positive correlated with PPROM cases with no other significant association or difference (Table 3).

Table (3): Comparison between both studied group as regard clinical and obstetric history

\begin{tabular}{|c|c|c|c|c|c|c|}
\hline & Variable & & No PPROM group & PPROM group & $\mathbf{X 2}$ & $\mathbf{P}$ \\
\hline \multirow{8}{*}{ Parity } & \multirow{2}{*}{ PG } & $\mathbf{N}$ & 79 & 8 & \multirow{8}{*}{6.25} & \multirow{8}{*}{0.081} \\
\hline & & $\%$ & $28.4 \%$ & $36.4 \%$ & & \\
\hline & \multirow{2}{*}{$\leq 2$} & $\mathbf{N}$ & 142 & 6 & & \\
\hline & & $\%$ & $51.1 \%$ & $27.3 \%$ & & \\
\hline & \multirow{2}{*}{$3-4$} & $\mathbf{N}$ & 50 & 8 & & \\
\hline & & $\%$ & $18.0 \%$ & $36.4 \%$ & & \\
\hline & \multirow{2}{*}{$>4$} & $\mathbf{N}$ & 7 & $\mathbf{0}$ & & \\
\hline & & $\%$ & $2.5 \%$ & $0.0 \%$ & & \\
\hline \multirow{4}{*}{ Previous PROM } & \multirow{2}{*}{ No } & $\mathbf{N}$ & 233 & 7 & \multirow{4}{*}{34.44} & \multirow{4}{*}{0.00 ** } \\
\hline & & $\%$ & $83.8 \%$ & $31.8 \%$ & & \\
\hline & \multirow{2}{*}{ Yes } & $\mathbf{N}$ & 45 & 15 & & \\
\hline & & $\%$ & $16.2 \%$ & $68.2 \%$ & & \\
\hline \multirow{4}{*}{ FH } & \multirow{2}{*}{ No } & $\mathbf{N}$ & 202 & 8 & \multirow{4}{*}{12.79} & \multirow{4}{*}{$0.00 * *$} \\
\hline & & $\%$ & $72.7 \%$ & $36.4 \%$ & & \\
\hline & \multirow{2}{*}{ Yes } & $\mathbf{N}$ & 76 & 14 & & \\
\hline & & $\%$ & $27.3 \%$ & $63.6 \%$ & & \\
\hline \multirow{8}{*}{ Risk } & \multirow{2}{*}{ No } & $\mathbf{N}$ & 101 & 6 & \multirow{8}{*}{6.0} & \multirow{8}{*}{0.11} \\
\hline & & $\%$ & $36.3 \%$ & $27.3 \%$ & & \\
\hline & \multirow{2}{*}{ Passive smoker } & $\mathbf{N}$ & 48 & 7 & & \\
\hline & & $\%$ & $17.3 \%$ & $31.8 \%$ & & \\
\hline & \multirow{2}{*}{ DM } & $\mathbf{N}$ & 36 & $\mathbf{0}$ & & \\
\hline & & $\%$ & $12.9 \%$ & $0.0 \%$ & & \\
\hline & \multirow{2}{*}{ Anemia } & $\mathbf{N}$ & 93 & 9 & & \\
\hline & & $\%$ & $33.5 \%$ & $40.9 \%$ & & \\
\hline \multirow{4}{*}{ IVF } & \multirow{2}{*}{ No } & $\mathbf{N}$ & 263 & 21 & \multirow{4}{*}{0.029} & \multirow{4}{*}{0.86} \\
\hline & & $\%$ & $94.6 \%$ & $95.5 \%$ & & \\
\hline & \multirow{2}{*}{ Yes } & $\mathbf{N}$ & 15 & 1 & & \\
\hline & & $\%$ & $5.4 \%$ & $4.5 \%$ & & \\
\hline
\end{tabular}


Preterm was significantly associated with PPROM also PPH was significantly associated with PPROM and CS as mode of delivery was significantly associated with PPROM. Birth weight and APGAR score were significantly lower among PPROM cases and NICU also baby mortality were significantly associated with PPROM (Table 4).

Table (4): Comparison between both studied group as regard maternal outcome and neonatal outcomes

\begin{tabular}{|c|c|c|c|c|c|}
\hline \multicolumn{3}{|c|}{ Variable } & $\begin{array}{c}\text { No PPROM group } \\
(\mathbf{N}=\mathbf{2 7 8})\end{array}$ & $\begin{array}{l}\text { PPROM group } \\
(\mathbf{N}=\mathbf{2 2})\end{array}$ & $P$ - value \\
\hline \multirow{4}{*}{ Preterm } & \multirow{2}{*}{ No } & $\mathbf{N}$ & 262 & $\mathbf{0}$ & \multirow{4}{*}{$0.00 * *$} \\
\hline & & $\%$ & $94.2 \%$ & $0.0 \%$ & \\
\hline & \multirow{2}{*}{ Yes } & $\mathbf{N}$ & 16 & 22 & \\
\hline & & $\%$ & $5.8 \%$ & $100.0 \%$ & \\
\hline \multirow{4}{*}{ PPH } & \multirow{2}{*}{ No } & $\mathbf{N}$ & 206 & 10 & \multirow{4}{*}{$0.004 *$} \\
\hline & & $\%$ & $74.1 \%$ & $45.5 \%$ & \\
\hline & \multirow{2}{*}{ Yes } & $\mathbf{N}$ & 72 & 12 & \\
\hline & & $\%$ & $25.9 \%$ & $54.5 \%$ & \\
\hline \multirow{4}{*}{ Mode } & \multirow{2}{*}{ NVD } & $\mathbf{N}$ & 150 & 4 & \multirow{4}{*}{$0.001 * *$} \\
\hline & & $\%$ & $54.0 \%$ & $18.2 \%$ & \\
\hline & \multirow{2}{*}{ CS } & $\mathbf{N}$ & 128 & 18 & \\
\hline & & $\%$ & $46.0 \%$ & $81.8 \%$ & \\
\hline \multicolumn{3}{|c|}{ Birth weight (gm) } & $3025.64 \pm 298.36$ & $2015.9 \pm 226.45$ & $\mathbf{0 . 0 0} * *$ \\
\hline \multicolumn{3}{|c|}{ APGAR score at $1 \mathrm{~min}$} & $7.19 \pm 0.84$ & $6.27 \pm 1.24$ & $\mathbf{0 . 0 0 * *}$ \\
\hline \multicolumn{3}{|c|}{ APGAR score at $5 \mathrm{~min}$} & $8.59 \pm 0.73$ & $7.72 \pm 1.38$ & $0.00 * *$ \\
\hline \multirow{4}{*}{$\begin{array}{c}\text { Baby } \\
\text { gender }\end{array}$} & \multirow{2}{*}{$\mathbf{M}$} & $\mathbf{N}$ & 125 & 6 & \multirow{4}{*}{0.107} \\
\hline & & $\%$ & $45.0 \%$ & $27.3 \%$ & \\
\hline & \multirow{2}{*}{$\mathbf{F}$} & $\mathbf{N}$ & 153 & 16 & \\
\hline & & $\%$ & $55.0 \%$ & $72.7 \%$ & \\
\hline \multirow{4}{*}{$\begin{array}{c}\text { NICU } \\
\text { admission }\end{array}$} & \multirow{2}{*}{ No } & $\mathbf{N}$ & 234 & 7 & \multirow{4}{*}{$<0.001 *$} \\
\hline & & $\%$ & $84.2 \%$ & $31.8 \%$ & \\
\hline & \multirow{2}{*}{ Yes } & $\mathbf{N}$ & 44 & 15 & \\
\hline & & $\%$ & $15.8 \%$ & $68.2 \%$ & \\
\hline \multirow{4}{*}{ Mortality } & \multirow{2}{*}{ Died } & $\mathbf{N}$ & 7 & 4 & \multirow{4}{*}{$<0.001 *$} \\
\hline & & $\%$ & $2.5 \%$ & $18.2 \%$ & \\
\hline & \multirow{2}{*}{ Survived } & $\mathbf{N}$ & 271 & 18 & \\
\hline & & $\%$ & $97.5 \%$ & $81.8 \%$ & \\
\hline
\end{tabular}


THE ROLE OF PLATELET COUNT AND MEAN PLATELET VOLUME... 63

ROC Curve for PLT cutoff regards PPROM

Significant AUC with cutoff $>258$ with sensitivity $83.3 \%$ and specificity $75.0 \%$ (Figure 1).

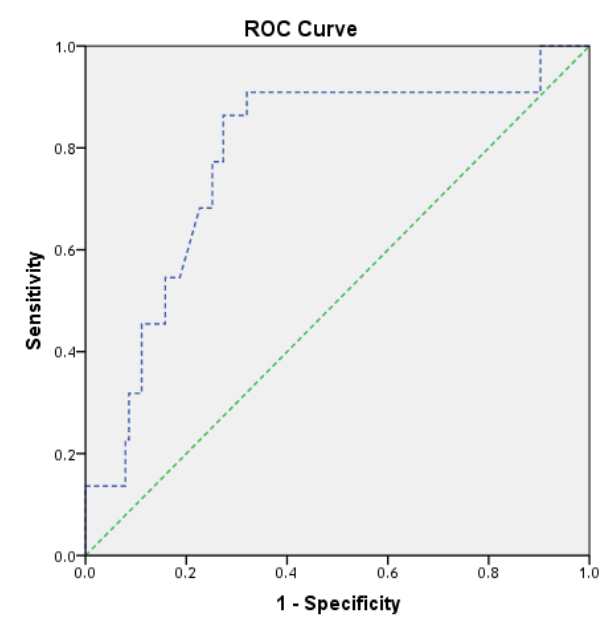

Diagonal segments are produced by ties.

Figure (1): Area under curve, cutoff and validity of PLT and MPV regard detection of PPROM

\begin{tabular}{|c|c|c|c|c|c|c|}
\hline \multirow{2}{*}{ Area } & \multirow{2}{*}{ Cutoff } & \multirow{2}{*}{$\mathbf{P}$} & \multicolumn{2}{|c|}{ 95\% Confidence Interval } & \multirow{2}{*}{ Sensitivity } & \multirow{2}{*}{ Specificity } \\
\hline & & & Lower Bound & Upper Bound & & \\
\hline 0.783 & $>258$ & $0.00 * *$ & 0.680 & 0.885 & $83.3 \%$ & $75.0 \%$ \\
\hline
\end{tabular}

ROC Curve for MPV cutoff regards PPROM

Significant AUC with cut off (Figure 2).

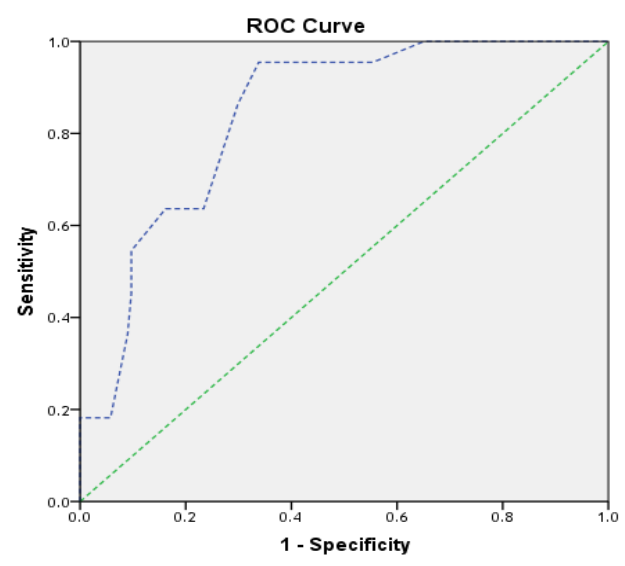

Diagonal segments are produced by ties.

Figure (2): Area under curve, cutoff and validity of MPV regard detection of PPROM

\begin{tabular}{|c|c|c|c|c|c|c|}
\hline \multirow{2}{*}{ Area } & \multirow{2}{*}{ Cutoff } & \multirow{2}{*}{$\mathbf{P}$} & \multicolumn{2}{|c|}{ 95\% Confidence Interval } & \multirow{2}{*}{ Sensitivity } & \multirow{2}{*}{ Specificity } \\
\cline { 4 - 5 } & & Lower Bound & Upper Bound & & \\
\hline $\mathbf{0 . 8 4 1}$ & $<\mathbf{8 . 7 5}$ & $\mathbf{0 . 0 0} * *$ & $\mathbf{0 . 7 7 4}$ & $\mathbf{0 . 9 0 8}$ & $\mathbf{8 7 . 0 \%}$ & $\mathbf{6 8 . 5 \%}$ \\
\hline
\end{tabular}




\section{DISCUSSION}

As regard age and gestational age distribution among the studied groups, the mean of the age was $26.89 \pm 4.42$ with minimum 19 and maximum 35 years; the Gestational age at the beginning was distributed as $12.3 \pm 0.99$ and at the end $37.3 \pm 2.26$. In this study, majority of parity was $\leq 2$ as it was represented $49.3 \%$ followed by $29.0 \%$ then $3-4$ with $19.4 \%$ and finally $>4$ with $2.3 \%$.

The study by Al Riyami et al. (2013) revealed that in order to reduce the risk of PPROM in future pregnancies, especially at extreme gestational age. In addition, the findings showed that women aged 30 years and older and nulliparous women were noted to be at an increased risk of extreme PPROM.

The obtained results by Guseinova and Khodzhaeva (2019) revealed a higher incidence of PPROM at 22-36 weeks gestation in first-time pregnant women, whereas PB with intact fetal membranes and term delivery were found among multiparous women. Most pregnant women with $\mathrm{PB}$ as a result of PPROM were in the most active reproductive age of 25-30 years $(60 \%)$.

According to the results of the study of foreign scientists Hailemariam et al. (2017) and Ibishi and Isjanovska (2015), it was revealed that the peak of occurrence of PPROM in incomplete pregnancy in $43 \%$ of cases was noted at the age of 2630 years.

In the study by Lorthe et al. (2018), it is concluded that with PPROM at 22-25 weeks' gestation, overall and for each GA at PPROM, nearly half of the fetuses were delivered within the first week. Obstetric management appears to be strongly influenced by GA at PPROM Overall. Also, PPROM at 22-25 weeks was associated with high frequencies of perinatal mortality and morbidity.

Both perinatal and childhood prognosis, related to all fetuses or to live born infants, significantly improved with advancing GA at PPROM. PROM is one of the causes of increased maternal and perinatal morbidity and mortality. The cause may not be known, but multiple risk factors abound (Lawan et al., 2019). As regard the clinical and obstetric history distribution, $20 \%$ of studied group had previous PROM, 30\% had positive $\mathrm{FH}$, $35.7 \%$ of studied group had no comorbidities, $34 \%$ had anemia and $18.3 \%$ had passive smoker and finally gestational DM was in $12 \%$, only $5.3 \%$ had IVF.

Lawan et al. (2019) in his study found that past obstetric performance is an important risk factor for PROM, and in keeping with other studies, we found previous history of PROM to be highly predictive of subsequent PROM which supported our results.

In consistent with our study, Caughey et al. (2010) found that the risk of recurrence of PROM ranges from $16 \%$ to $32 \%$ when compared with $4 \%$ in women with previously uncomplicated pregnancy.

The recurrence of PROM may be associated with an underlying pathology or unforeseen genetic factor that has persisted in the subsequent pregnancies. A proper evaluation in to the possible cause of PROM and its subsequent elimination may change the course of future pregnancies. 


\section{THE ROLE OF PLATELET COUNT AND MEAN PLATELET VOLUME... 65}

Bouvier et al. (2019) and Whynott et al. (2017) in their study confirmed the most known risk factors for PPROM, such as BMI $<18.5 \mathrm{~kg} / \mathrm{m} 2$, history of PPROM or prematurity, nulliparity, multiple pregnancies, low level of education, and infections. These results, as well as the percentage of PPROM (2.7\%).

The American Association of Obstetricians and Gynecologists cited data according to which PPROM with history of PB increases the risk of "recurrence" of PPROM by 16-32\% (American College of Obstetricians and Gynecologists, 2016).

According to the maternal outcome distribution among studied group, $12.7 \%$ had preterm labor, $7.3 \%$ had PPROM, $28 \%$ had PPH and 51.3\% had NVD and CS was $48.7 \%$ and as regard the baby outcome distribution, female baby were $56.3 \%$ and male represent $43.7 \%$, NCIU was needed by $19.7 \%$ regard survival $3.7 \%$ died and $96.3 \%$ survived.

Online with our study results, three retrospective studies, Palmer et al. (2017) and Beckmann et al. (2010) have shown that maternal outcomes (chorioamnionitis, mode of delivery) and neonatal outcomes (hospitalization in intensive care units, respiratory distress syndrome, intraventricular hemorrhage).

PROM accounts for $25-40 \%$ of all preterm deliveries that increase the risk of neonatal morbidity by $75 \%$. In addition, improvement in survival may be associated with adverse long term sequels needing more treatment and NICU hospitalization. In accordance with our study, Afrasiabi et al. (2014) reported that there were 489 babies hospitalized in NICU for 1 to 54 days; $28.42 \%$ born were preterm, 308 with birth weight $<2500$ gram and 170 with birth weight between 2500 and 4000 gram.

In our study, age was significantly higher among PROM cases but GA at the end was significantly lower at PPROM group and there was no significant difference between groups regard GA at the beginning. In the study by Ibrahiem et al. (2020), there was statistically significant difference between the two groups as regards gestational age at delivery and latency period with significant increase in study group than control. The latency time between PPROM and delivery seems to be a key point to improve perinatal morbidity and mortality. Increase of this period could help attending physicians in PPROM management.

In agreement with those studies, Luzi et al. (2018) study showed a statistically significant increase $(p=0.04)$ of delivery gestational age.

The study by Nageeb et al. (2020) which supports our results found that the gestational age at ROM was significantly lower and the latent period was significantly shorter in patients delivering before 34 weeks of gestation ( $p$-values $<0.001)$.

As regard our study, Previous PROM and positive family history were significantly positive correlated with PPROM cases with no other significant association or difference.

In accordance with our study results, Assefa et al. (2018), Choudhary et al. (2015) and Tarek et al. (2012) showed that previous PROM to be the strongest risk factor for premature ruptures of membranes. Women who had previous 
PROM were 4.45 more likely to develop PROM with AOR 4.45 (CI: 1.87, 10.6). This might be due to untreated genitourinary infection and a short cervical length. In addition, obstetric problems are recurrent by nature.

In our study, preterm was significantly associated with PPROM also PPH was significantly associated with PPROM and CS as mode of delivery was significantly associated with PPROM. In the study by Ibrahiem et al. (2020), there was statistically highly significant difference between the two groups regarding spontaneous delivery and cesarean section (CS) with low incidence of CS among study group (27.2\%) and high incidence of CS among control group (44.1\%) unlike our study results.

Our study is counteracting a study by Kunze et al. (2016) conducted on 1026 cases with PROM. In their study they reported a cesarean section rate of $(27 \%)$.

Our study showed that birth weight and APGAR score were significantly lower among PPROM cases and NICU also baby mortality were significantly associated with PPROM. The study by Nageeb et al. (2020) found that The Apgar score at 1 and 5 minutes as well as the birth weight were significantly lower in the group delivering before 34 weeks of gestation ( $\mathrm{p}$-values <0.001).

PROM accounts for $25-40 \%$ of all preterm deliveries that increase the risk of neonatal morbidity by $75 \%$. In addition, improvement in survival may be associated with adverse long term sequels needing more treatment and NICU hospitalization. In accordance with our study, Ibrahiem et al. (2020) revealed significant relation between length of neonatal NICU stay and maternal PROM. Afrasiabi et al. (2014) reported that there were 489 babies hospitalized in NICU for 1 to 54 days; $28.42 \%$ born were preterm, 308 with birth weight $<2500$ gram and 170 with birth weight between 2500 and 4000 gram. There was a $(\mathrm{P}=0.001)$ and significant relation between length of neonatal NICU stay and maternal PROM.

PLT was significantly higher among PPROM cases but MPV was significantly lower among PPROM cases with no other significance between groups. Tzur et al. (2013) investigated maternal leukocyte count in the first trimester of pregnancy and the risk for development of obstetric complications. In their study, a significant association was observed between leukocytosis during the first trimester and PPROM. According to these reports, it is evident that there is a strong relevance between levels of inflammation markers and occurrence of PPROM as a result of up regulated secretion by cytokines.

There are few reports about the relationship between MPV and morbidities among large cohorts of premature newborns. Cekmez et al. (2013) found that elevated MPV measured within $2 \mathrm{~h}$ of birth was associated with BPD, IVH, and NEC using univariate analysis in $44 \mathrm{BPD}, 42 \mathrm{IVH}$, and $21 \mathrm{NEC}$ preterm newborns, but they did not perform multivariate analysis.

As regard the area under curve, cutoff and validity of PLT regard detection of PPROM, Significant AUC with cutoff $>258$ with sensitivity $83.3 \%$ and specificity $75.0 \%$.

In the study by Ekin et al. (2015), The cut-off values of MPV $\leq 8.6 \mathrm{fL}$ and platelet count $\geq 216 \times 103 / \mu \mathrm{L}$ predicted $\mathrm{PPROM}$ 
with a sensitivity of $58 \%$ and $65 \%$, a specificity of $62 \%$ and $44 \%$, a positive predictive value of $56 \%$ and $49 \%$, a negative predictive value of $64 \%$ and $60 \%$, positive likelihood ratio of 1.56 and 1.16 and negative likelihood ratio of 0.66 and 0.8 , respectively.

The overall accuracy of MPV for detecting PPROM was found to be superior to platelet count. Early identification in the first trimester of pregnancy of patients at risk of PPROM is of great importance as preventive interventions could be offered to these patients. The estimated detection rates of PPROM were mostly based on maternal characteristics and obstetric history. Among these, history of an earlier preterm labor or PPROM is the strongest risk factor (Toprak et al., 2017).

Early MPV decrement with a high platelet count in the prediction of PPROM can be explained by reactive thrombocytosis. It is a benign form of thrombocytosis secondary to medical or surgical conditions. According to this, there is an inverse relation between platelet count and MPV (Ekin et al., 2015).

Approximately one half of PPROM cases are associated with intraamniotic infection, which are mostly subclinical in nature. In cases of intra-amniotic infection, proinflammatory and immunoregulatory cytokines are produced within the uterine cavity and then they reach the maternal circulation. Overproduction of cytokines, such as interleukin (IL)-4, IL-6 and tumor necrosis factor, influence platelet characteristics by interfering with megakaryopoiesis and subsequent release of predominantly small platelets from the bone marrow. Another evidence was about thrombopoietin, which is the major hormone that regulates platelet production by acting at earlier stages of megakaryopoiesis (Nageeb et al., 2020).

\section{CONCLUSION}

This is a second study that measures the predictability of PPROM with platelet count and MPV in maternal serum during the first trimester. We found that plasma MPV could be used as a more efficient indicator for an early diagnosis of PPROM than platelet count. Thus, our study can serve as a reference data for clinical practice in detecting those asymptomatic women with subclinical intra-amniotic infection at increased risk for PPROM and subsequent preterm delivery. MPV is a cheap, rapid and easily applicable test for determining the patients at risk for PPROM. Due to multifactorial origin of PPROM, early detection of all patients with a single test is rather difficult. In order to develop an accurate and efficient method in the estimation of the risk of PPROM, screening strategies combining MPV with other biological markers should be considered.

\section{REFERENCES}

1. Afrasiabi N, Mohagheghi $P$ and Kalani $M$. (2014): The Effect of High Risk Pregnancy on Duration of Neonatal Stay in Neonatal Intensive Care Unit. Iran J Pediatr., 4: 423428.

2. Agrawala $V$ and Hirsch E. (2012): Intrauterine infection and preterm labor. Semin Fetal Neonatal Med, 17(1): 12-19.

3. Al-Riyami L, Pineda MA, Rzepecka J and Huggan JK. (2013): Designing antiinflammatory drugs from parasitic worms: a synthetic small molecule analogue of the Acanthocheilonema viteae product ES-62 
prevents development of collagen-induced arthritis. J Med Chem., 56: 9982-10002.

4. American College of Obstetricians and Gynecologists' (ACOG) Committee on Practice Bulletinsd Obstetrics. (2016): Practice Bulletin No. 172: Premature rupture of membranes. Obstet Gynecol., 128: 165-77.

5. Assefa NE, Berhe $H$ and Girma F. (2018): Risk factors of premature rupture of membranes in public hospitals at Mekele city, Tigray, a case control study. BMC Pregnancy Childbirth, 1: 386-92.

6. Beckmann MW, Wiegratz I, Dereser MM, Baier $P$ and Born HJ. (2010): Diagnostik des Blasensprungs: Vergleich des vaginalen Nachweises von fetalem Fibronectin und der intraamnialen Injektion von Indigo Carmine. Geburtshilfe Frauenheilk., 53: 86-91.

7. Bouvier D, Forest JC, Blanchon $L$ and Bujold E. (2019): Risk Factors and Outcomes of Preterm Premature Rupture of Membranes in a Cohort of 6968 Pregnant Women Prospectively Recruited. J Clin Med., 8(11): 1987-92.

8. Calvin SE and Oyen ML. (2010): Microstructure and Mechanics of the Chorioamnion Membrane with an Emphasis on Fracture Properties. Annals of the New York Academy of Sciences, 1101(1): 166-85.

9. Caughey AB, Robinson JN and Norwitz ER. (2010): Contemporary Diagnosis and Management of Preterm Premature Rupture of Membranes. Rev Obstet Gynecol., 1: 1122.

10. Cekmez F, Tanju IA and Canpolat FE. (2013): Mean platelet volume in very preterm infants: a predictor of morbidities? Eur Rev Med Pharmacol Sci., 17: 134-7.

11. Choudhary M, Rathore SB and Chowdhary J. (2015): Pre and post conception risk factors in PROM. IJRMS, 3: $10-15$.

12. Ekin A, Gezer C and Kulhan G. (2015): Can platelet count and mean platelet volume during the first trimester of pregnancy predict preterm premature rupture of membranes? J Obstet Gynaecol Res., 41(1): 23-8.
13. Gasparyan AY, Ayvazyan L, Mikhailidis DP and Kitas GD. (2011): Mean platelet volume: A link between thrombosis and inflammation. Curr Pharm Des., 17: 47-58

14. Guseinova GE and Khodzhaeva ZS. (2019): Clinical and anamnestic features of women with preterm premature rupture of membranes. Obstetrics and Gynecology Scientific and Practical Journal (Moscow), 8: 54-61.

15. Hailemariam SA, Diriba TD and Yesuf EA. (2017): Incidence, Maternal and Perinatal Outcome of Premature Rupture of Fetal Membrane Cases in Jimma University Teaching Hospital, South West Ethiopia. EC Gynaecology, 5: 163-172

16. Ibishi VA and Isjanovska RD (2015): Prelabour Rupture of Membranes: Mode of Delivery and Outcome. Open Access Maced J Med Sci., 2: 237-240.

17. Ibrahim FA, Mostafa MK and Farahat MM. (2020): Vaginal Probiotic Administration in The Management of Preterm Premature Rupture of Membranes. The Egyptian Journal of Hospital Medicine, 10: $672-7682$.

18. Kale A, Kale E and Akdeniz N (2007): Proposal of a diagnostic test for the detection of preterm premature rupture of membranes based on the determination of thyroid hormones in vaginal washing fluid. Fetal Diagn Ther., 22(5): 330-4.

19. Kunze M, Klar M, Morfeld CA, Thorns B, Schild RL and Markfeld-Erol F. (2016): Cytokines in noninvasively obtained amniotic fluid as predictors of fetal inflammatory response syndrome. Am J Obstet Gynecol., 215: 96-102.

20. Lawan ZM, Bako B, Idrisa A and Bukar M. (2019): Risk factors of prelabor rupture of membranes at University of Maiduguri Teaching Hospital, Maiduguri: A crosssectional study. Tropical Journal of Obstetrics and Gynaecology, 2: 293-298.

21. Lorthe E, Torchin H, Delorme $P$ and Subtil D. (2018): Preterm premature rupture of membranes at 22-25 weeks' gestation: perinatal and 2-year outcomes within a 
national population-based study (EPIPAGE2). American Journal of Obstetrics and Gynecology, 3: 298-314.

22. Luzi G, Iazzetta E and Cecconi L. (2018): Lactobacillus Rhamnosus BMX 54 Vaginal application usefulness as adjuvant therapy for Preterm Premature Rupture of Membranes (PPROM) in the second Trimester of Pregnancy. Int J Ped \& Neo Heal., 1: 15-20.

23. Nageeb AH, Fares MA and Islam BA. (2020): Fetal and Maternal Outcome in Preterm Premature Rupture of Membranes (PPROM) at Ain Shams Maternity Hospital: A Retrospective Analysis of Last Five Years Admissions. International Journal of Medicine, 133: 1-8.

24. Palmer L, Grabowska $K$ and Burrows J. (2017): A retrospective cohort study of hospital versus home care for pregnant women with preterm prelabor rupture of membranes. Int J Gynaecol Obstet., 2: 180184.
25. Tarek KA, Sahar NM and Hamida AE. (2012): Cervicovaginal Infection during Pregnancy and Its Relation to Preterm PreLabour Rupture Of Membranes. J Am Sci., 8(12): 15-19.

26. Toprak E, Bozkurt M, Cakmak BD and Özçimen E. (2017): Platelet to Lymphocyte Ratio: A New Inflammatory Marker For Diagnosis of Preterm Premature Rupture of Membranes, 18; 3: 122-126.

27. Tzur T, Weintraub AY and Sergienko R. (2013): Can leukocyte count during the first trimester of pregnancy predict later gestational complications? Arch Gynecol Obstet., 3: 421-7.

28. Whynott RM, Vaught KCC and Segars JH. (2017): The Effect of Uterine Fibroids on Infertility: A Systematic Review. Semin. Reprod., 35: 523-532.

29. Yeh CC, Chen CY and Wang PH. (2017): Infection and preterm birth. J Chin Med Assoc., 80(9): 530-531. 
دور عدد ومتوسط حجم الصفائح الدموية خلال الثلث الأول من الحمل فى توقع التمزق المبكر لأغشية المحيطة بالجنين

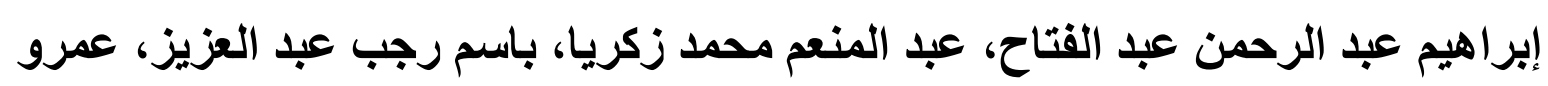

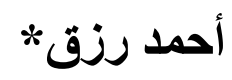

قسمي التوليد وأمر اض النساء و الباثولوجيا الإكلينكيةث، كلية الطب، جامعة الأزهر

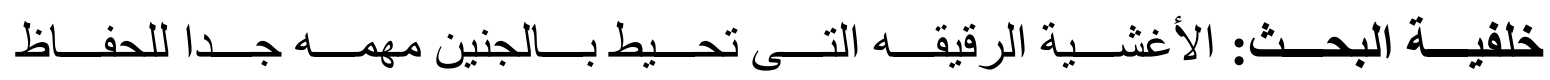

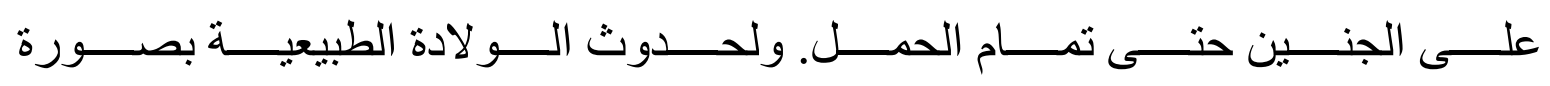

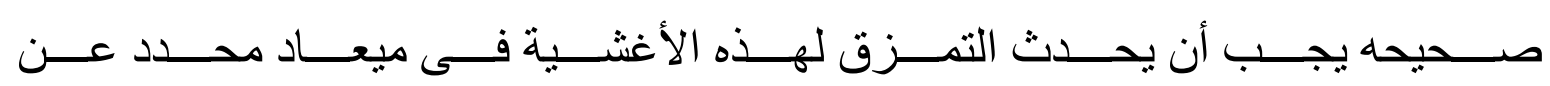

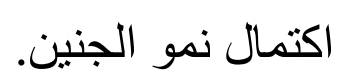

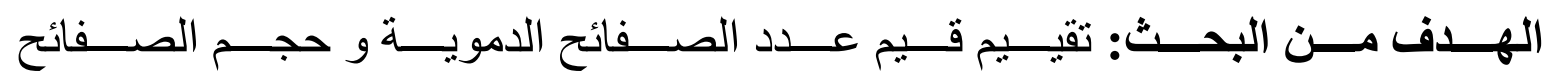

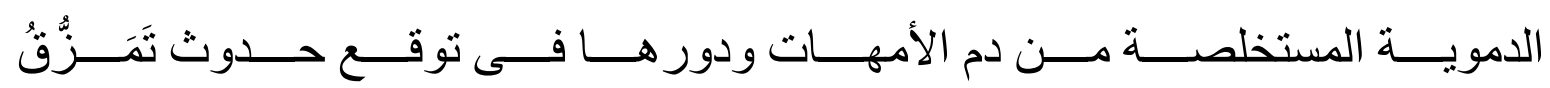

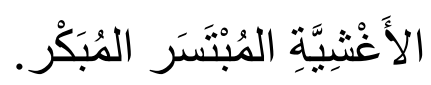

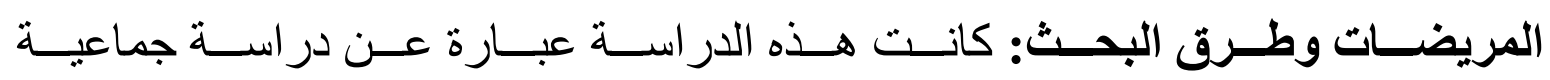

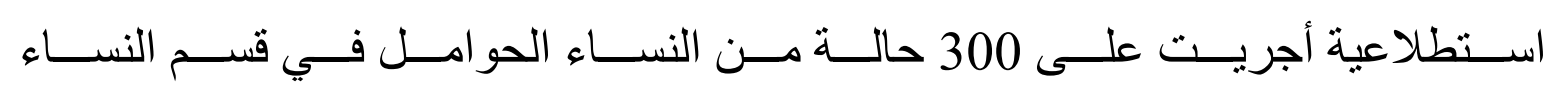

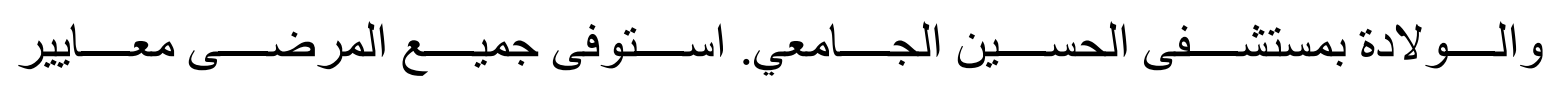

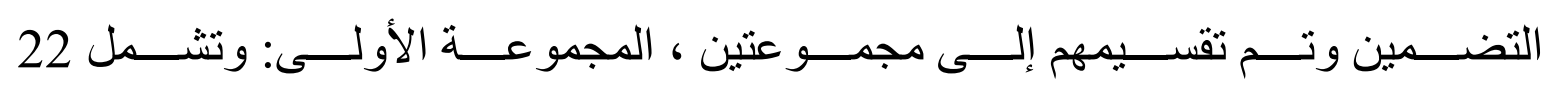

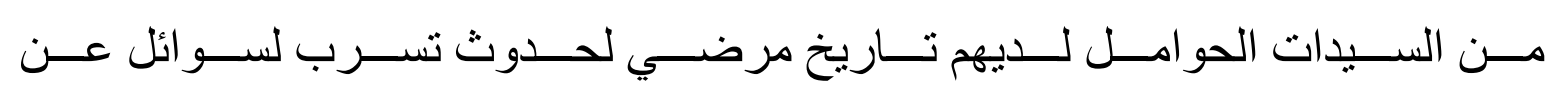

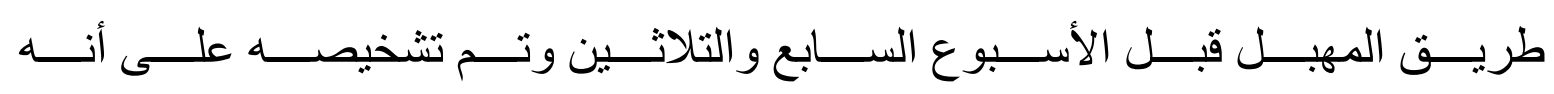

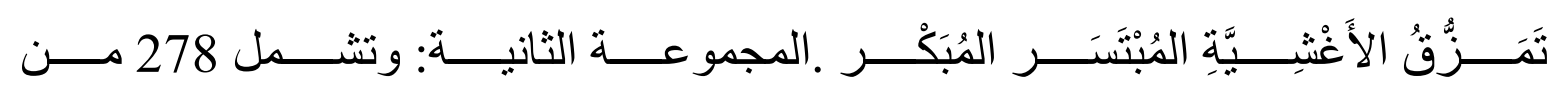

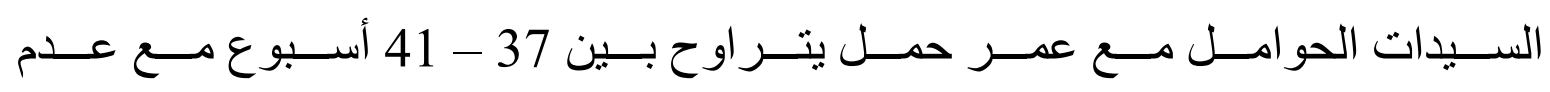

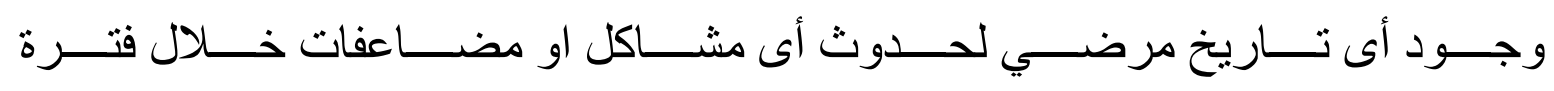

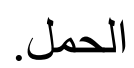


THE ROLE OF PLATELET COUNT AND MEAN PLATELET VOLUME... 71

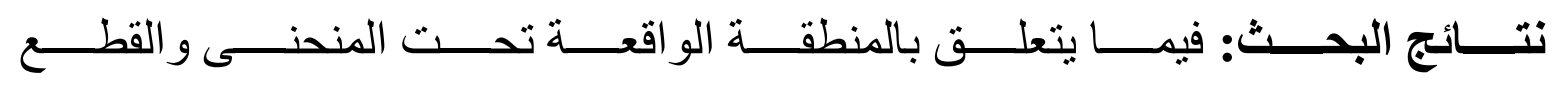

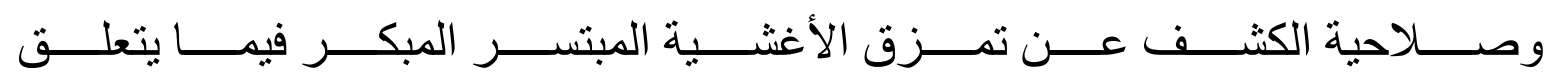

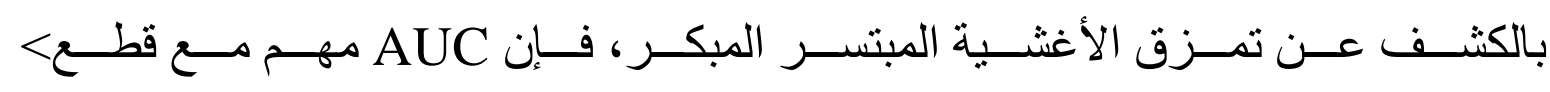

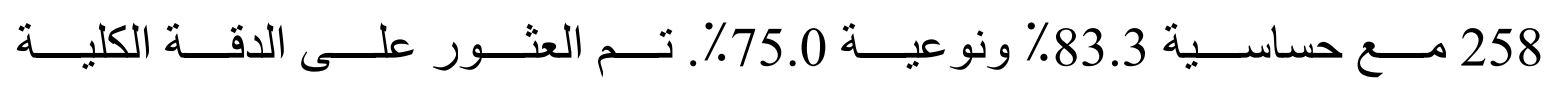

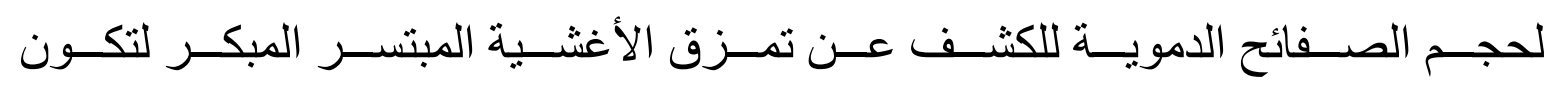
أعلى من عدد الصفائح الدموية.

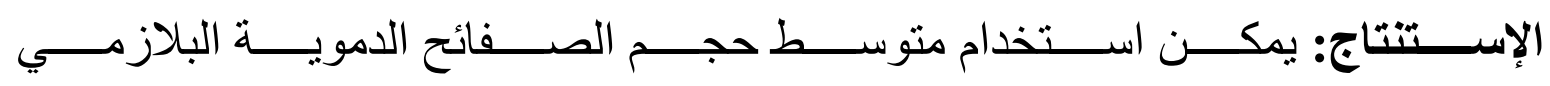

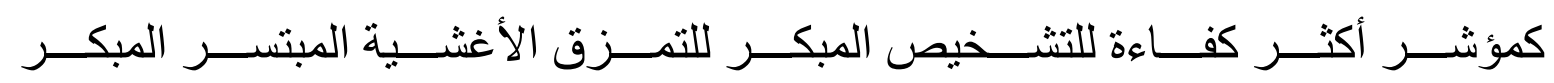

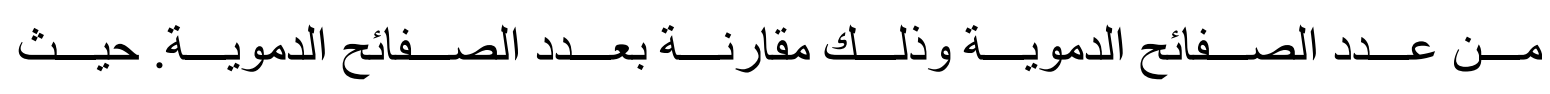

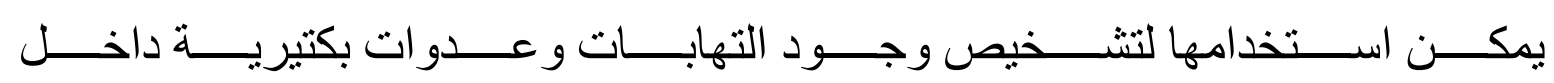
السائل الأمنيوسي.

الكلمـــات الدالــة: تمــزف الأغثــية المبتشــر المبكــر , عــدد الصــفائح الدمويـــة, حجم الصفائح الدموية خلال الأثهر الثانثة الأولى. 